\title{
Desenvolvimento da atenção mediada e sua relação com práticas pedagógicas
}

\author{
Lucimar Delman Lains, (D) * Maria Silvia Pinto de Moura Librandi da Rocha \\ Pontifícia Universidade Católica de Campinas, Campinas, SP, Brasil
}

\section{Resumo}

Trata-se de apresentação de resultados de pesquisa fundamentada na abordagem histórico-cultural, desenvolvida com uma turma de crianças de cinco a seis anos, em uma escola de educação infantil no município de Campinas/SP, e sua respectiva professora. O objetivo foi investigar as possibilidades de desenvolvimento da atenção mediada em crianças através de práticas pedagógicas. O material empírico foi produzido por meio de encontros preparatórios com a professora para a realização de atividades, observação participante durante as atividades desenvolvidas (sete semanas) e entrevistas com a professora, no início, meio e final do período de permanência em campo. O material empírico foi analisado qualitativamente, utilizando-se elementos da abordagem microgenética. Os resultados da pesquisa demonstram que o aprimoramento da mediação e das práticas pedagógicas na educação infantil poderá oferecer maiores contribuições para o desenvolvimento infantil, bem como novas perspectivas para o estudo da atenção mediada ou superior, segundo nomenclatura de L. S. Vigotski.

Palavras-chave: atenção mediada; práticas pedagógicas; teoria histórico-cultural.

\section{The mediated attention development and the relationship with educational practices}

\begin{abstract}
It is the presentation of search results based on the cultural-Historical approach, developed with children of five to six years in a school of Early Childhood Education in Campinas/SP and their respective teacher. The objective was to investigate the possibilities of mediated attention development in children through pedagogical practices. The empirical material was produced by preparatory meetings with the teacher to carry out activities, participant observation during the activities (seven weeks) and interviews with the teacher at the beginning, middle and end of the field in length of stay. The empirical material was analyzed qualitatively, using elements of microgenetic approach. The survey results show that the improvement of mediation and pedagogical practices in early childhood education may offer greater contributions to child development as well as new perspectives for the study of mediated or greater attention, according to nomenclature of L. S. Vygotsky.
\end{abstract}

Keywords: mediated attention; pedagogical practices; cultural-historical theory.

\section{Introdução}

A atenção, condição básica para a aprendizagem e realização de atividades cotidianas e escolares, tem estado entre os principais motivos de queixa dos professores, da qual têm derivado muitos encaminhamentos de crianças para especialistas (psicopedagogos, psicólogos e médicos), com a expectativa de que estes profissionais possam resolver as dificuldades. Nesta dinâmica, muitos alunos têm sido submetidos a constantes rotulações, diagnósticos e medicalização, por certos comportamentos considerados como inadequados e/ou insuficientes para o bom desempenho escolar. A falta ou a dificuldade de manter a atenção em atividades pedagógicas tem sido relacionada cada vez mais frequentemente ao que se nomeia como "transtorno do déficit de atenção e hiperatividade" - TDAH, que, segundo Barkley (2002, p. 23), é "um transtorno de desenvolvimento do autocontrole que consiste em problemas com os períodos de atenção, com o controle do impulso e com o nível de atividade".

Artigos publicados e pesquisas realizadas em escolas brasileiras demonstram que há uma tendência entre os professores de atribuírem sucessos e fracassos da

\footnotetext{
^Endereço para correspondência: Pontifícia Universidade Católica de Campinas Rua Professor Doutor Euryclides de Jesus Zerbini. Parque Rural Fazenda Santa Cândida - Campinas, SP - Brasil. CEP: 13087-571.E-mails: lucimarlains@ gmail.com, silrocha@uol.com.br
}

Os dados completos das autoras encontram-se ao final do artigo. capacidade atencional e da aprendizagem às crianças, como resultantes de características individuais, desconsiderando as influências do meio, das interações, das práticas pedagógicas e dos contextos sociais nos quais estão inseridas (dentre vários artigos, destacamos EIDT; TULESKI; FRANCO, 2014; LEITE; TULESKI, 2011; EIDT; TULESKI, 2010; TULESKI; EIDT, 2007; EIDT; FERRACIOLI, 2007; BONDEZAN, 2006). Autoras de trabalhos críticos inaugurais de oposição a este modelo de responsabilização dos alunos quanto a dificuldades na escolarização, Moysés e Collares (1997, p. 63) há décadas evidenciam que "a instituição escolar é, na fala destes atores [professores, gestores, especialistas], praticamente isenta de responsabilidades. A escola, o sistema escolar são sistematicamente relegados a plano mais que secundário quando falam sobre o que consideram causas do fracasso escolar".

Eidt e Tuleski (2010) e Leite e Tuleski (2011), em suas pesquisas, redimensionam a compreensão sobre o TDAH a partir da teoria histórico-cultural, com reflexões acerca do processo ensino-aprendizagem e o desenvolvimento das funções psicológicas superiores (a imaginação, a linguagem, o pensamento, a sensação, a percepção, a memória e a atenção voluntárias). Apontando para a importância de uma nova compreensão sobre os problemas da atenção e dos comportamentos avalia- 
dos como hiperativos, permitem-nos vislumbrar as potencialidades do planejamento de práticas capazes de promover seu desenvolvimento.

Vygotski (1996) afirma que as funções psicológicas superiores formam-se nas interações e por meio delas, as quais se estabelecem entre sujeitos e entre estes e a realidade objetiva; então, é preciso adentrar as interações para, nelas, poder vislumbrar as possibilidades que se abrem à educação escolar e atuar sobre elas. Nessa concepção de desenvolvimento das funções psicológicas superiores deve-se levar em conta, de um lado, o impacto das relações sociais e da cultura na atualidade e, de outro lado, a influência da educação escolar nesse desenvolvimento (BONDEZAN, 2006).

$\mathrm{O}$ desenvolvimento da atenção é considerado pela teoria histórico-cultural um processo duplamente mediado: por instrumentos e signos e pela qualidade das mediações que circunscrevem o cotidiano das crianças. Este modelo teórico nos incita e nos ajuda, portanto, a argumentar que a escola e seus professores devem assumir papel ativo e nuclear na formação e desenvolvimento das funções psicológicas superiores nas novas gerações, visando à reprodução e ressignificação das qualidades humanas, histórica e culturalmente criadas. A atenção é considerada um dos aspectos mais importantes da atividade consciente do homem (LURIA, 1979), crucial para a organização de seu comportamento e de suas capacidades psicológicas. As informações e estímulos que recebemos do meio exterior a todo o momento precisam ser selecionados; precisamos reter os mais importantes e descartar os demais. Porém, esta capacidade não se constitui espontaneamente, como mera decorrência do amadurecimento orgânico e/ou da experiência empírica cotidiana de cada sujeito; ao contrário, é fruto de um longo processo de desenvolvimento social, histórico e cultural (VYGOTSKI, 1996).

A atenção, no início da vida de cada sujeito, é um processo marcadamente orgânico, "de crescimento, maturação e desenvolvimento dos aparatos nervosos e das funções da criança" (VYGOTSKI, 1996, p. 148). Essa gradativa maturação não se interrompe ao longo da infância e da vida adulta, mas é transformada e deslocada para segundo plano, pois o processo atencional, gradualmente, passa a ser dirigido por fatores sociais e culturais, que impõem novas tarefas para as quais a criança necessitará de regulação efetiva de seu comportamento e atenção. Assim, num longo processo de desenvolvimento, novas condutas vão sendo apropriadas, sempre mediadas pelos elementos da cultura e pelas pessoas com as quais cada sujeito convive.

Luria (1979, p. 1) define a atenção como

[...] a seleção da informação necessária, o asseguramento dos programas seletivos de ação e a manutenção de um controle permanente sobre eles [...]. O caráter seletivo da atividade consciente, que é função da atenção, manifesta-se igualmente na nossa percepção, nos processos motores e no pensamento.

Nenhuma atividade poderia ser realizada caso não existisse a seletividade promovida pela atenção, uma vez que a quantidade de informações que chegam ao homem do meio exterior é demasiadamente grande e desorganizada; a atenção regula, controla e organiza a atividade do homem.

Dois grupos de fatores determinam a atenção humana: o primeiro é constituído pela "estrutura dos estímulos externos", das informações que externamente chegam ao homem. No início do desenvolvimento estes estímulos exteriormente perceptíveis determinam o sentido, o objeto e a estabilidade da atenção. Fatores como a intensidade (grandeza, coloração, etc.) e a novidade (algo incomum ou novo que surja entre estímulos bem conhecidos e a ausência ou cessação do estímulo), controlam a atenção. A organização estrutural também afeta a capacidade atencional: um grande número de estímulos dispersos não pode ser percebido com êxito, mas se estiverem organizados em determinadas estruturas podem ser percebidos adequadamente.

O segundo grupo que determina a atenção do homem se refere à "atividade do próprio sujeito", que envolve a influência exercida pelas suas necessidades de ordem biológica, cultural e/ou social, sentimentos, expectativas, motivos, suas experiências anteriores, a relevância da tarefa desempenhada, interesses e objetivos sobre o processo de sua atividade. Como esclarece Luria (1979, p. 5-6)

[...] a "organização estrutural da atividade humana" é de importância essencial para a compreensão dos fatores que dirigem a atenção do homem. É sabido que a atividade do homem é condicionada por necessidades ou motivos visando um "objetivo" determinado. [O autor conclui que] a atenção do homem é determinada por sua atividade, reflete seu processo e lhe serve de mecanismo de controle.

$\mathrm{Na}$ teoria histórico-cultural distinguem-se dois tipos básicos de atenção: a "involuntária”, também denominada natural, inata, imediata ou inferior, e a "voluntária", também denominada arbitrária, mediada, cultural ou superior. Esses dois tipos de atenção não se separam por completo durante todo o percurso de desenvolvimento do homem; ao contrário, caminham articulados na construção de formas mais estáveis de comportamento, ação e regulação da conduta, conforme os aportes dessa teoria. Essa distinção entre atenção involuntária e atenção voluntária reserva a maior complexidade sobre o entendimento do desenvolvimento da atenção, sintetizada na seguinte questão: como o indivíduo se liberta do padrão responsivo estímulo-resposta e conquista a liberdade de escolher intencionalmente aquilo sobre o que prestar atenção?

Vygotski (1996) salienta que o desenvolvimento da atenção da criança, desde os primeiros dias de sua vida, se encontra em um meio complexo formado por estímulos de duplo gênero: os objetos e os eventos ambientais que atraem sua atenção em virtude de suas propriedades intrínsecas e a palavra do "outro". Primeiro os estímulos e as pessoas de seu entorno dirigem o seu comportamento atencional, mas à medida que vai dominando a linguagem -domínio aprendido nas relações sociais - começa a dominar a capacidade de dirigir sua atenção em relação aos outros e depois em relação às suas próprias funções psicológicas. 
Vygotski (1996) argumenta, assim, que a atenção voluntária é um processo mediado; para analisar a capacidade de atenção de cada sujeito é necessário considerar a qualidade das mediações, dos signos e instrumentos culturais aos quais ele teve acesso e de que vai se apropriando no percurso de seu desenvolvimento; argumenta também que esse processo subordina-se às leis gerais do desenvolvimento cultural e à constituição de formas superiores de conduta. De acordo com Vygotski (1996) devemos encarar o estudo da atenção como o de um produto de desenvolvimento cultural da criança, considerando-a como um modo de adaptação à vida social.

É necessário, entretanto, ressaltar que nos estudos pioneiros dos autores da teoria histórico-cultural, referentes ao desenvolvimento da atenção, sobretudo nos realizados por Luria (1979), examinam-se, mais detidamente, as mediações do outro pela linguagem no início da constituição da atenção mediada e em situação experimental. Argumentamos que a participação em experiências e vivências sistematizadas e intencionalmente organizadas pelo professor na educação infantil abre múltiplas oportunidades para o desenvolvimento da atenção e não se encontra explorada nos trabalhos dos autores fundadores da teoria histórico-cultural. Tampouco se pode dizer que a bibliografia nacional contemporânea sobre a atenção, quando referenciada nessa perspectiva teórica, seja robusta. Ao contrário, o conjunto de pesquisas com esses recortes ainda é modesto, e parece ser consensual entre os autores que os resultados já produzidos são ainda iniciais, preliminares, e requerem aprofundamento, novas análises e sínteses.

Os estudos que se desenvolvem no cruzamento entre teoria histórico-cultural, constituição/desenvolvimento da atenção mediada e práticas pedagógicas ${ }^{1}$ têm em comum as seguintes concepções:

1. o ensino (em especial o escolar) deve ser fonte de desenvolvimento e não um processo independente e/ou decorrente deste;

2. é possível desenvolver a atenção através de práticas pedagógicas;

3. o desenvolvimento da atenção voluntária em contexto escolar é mais profícuo quando ocorre por demanda de atividades significativas, por meio de tarefas de ensino planejadas e executadas pelo professor;

4. os docentes, embora sejam unânimes em considerar que para estudar é essencial manter uma atenção prolongada e focada, raramente ensinam seus alunos sobre como/o que devem fazer para conseguir desenvolver a referida capacidade atencional;

5. as pesquisas podem/devem contribuir para a consecução de transformações na realidade escolar pela via da instrumentalização teórica da atuação docente.

\footnotetext{
'Neste campo, recomenda-se a leitura dos seguintes trabalhos: Rosa (2011), Lucena (2016), Rabatini (2016) e Ferracioli (2018).
}

Fractal, Rev. Psicol., v. 32 - n. 1, p. 21-30 2020
Alinhamo-nos com essas concepções, e elas subjazem ao principal objetivo de nossa pesquisa: investigar as possibilidades de desenvolvimento da atenção mediada em crianças em um contexto de educação infantil e sua relação com as práticas pedagógicas, fundamentando-nos na teoria histórico-cultural.

\section{Método}

No desenvolvimento da pesquisa de campo, trabalhamos com uma turma composta por vinte e quatro crianças de cinco a seis anos e sua respectiva professora, em uma escola de educação infantil, localizada em um bairro da periferia do município de Campinas/SP. Para a escolha da escola, três fatores foram relevantes: há oito anos a segunda autora do artigo supervisionava grupos de alunos de graduação em Psicologia que realizavam estágio nesta unidade; portanto, havia um conhecimento prévio entre escola e pesquisadora. Embora a definição da turma tenha decorrido da faixa etária que nos interessava, a adesão da professora à proposta foi plena; e, apesar de não ter havido uma demanda específica da escola e/ou da professora quanto a problemas atencionais dos alunos, quando apresentado o projeto de pesquisa para a equipe técnico-pedagógica, foi unânime a manifestação sobre a importância de estudos sobre a atenção e de práticas pedagógicas favoráveis a seu desenvolvimento.

A pesquisa incluiu intervenção no cotidiano dessa turma, com o propósito de provocar e analisar transformações nos modos pelos quais as crianças prestavam atenção em certos aspectos do contexto e em seu próprio funcionamento psíquico. Inicialmente elegemos sete atividades que nos pareceram profícuas para o desenvolvimento da atenção e as compartilhamos com a professora, em dois encontros de preparação para que fossem inclusas em suas práticas pedagógicas; posteriormente, a professora as colocou em funcionamento com as crianças de sua turma, e realizamos observações dessas práticas nos momentos de interação entre crianças e professora, de modo a compreender a dinâmica e as relações estabelecidas entre elas. Estas atividades foram realizadas em dez encontros, ao longo de sete semanas, na maior parte das vezes com o grupo completo, de vinte e quatro alunos. Realizamos também três entrevistas com a professora, buscando conhecer suas concepções sobre a atenção e a importância do trabalho docente para desenvolvê-las. No presente texto recortamos da pesquisa episódios de atividades realizadas pela professora com a sua turma.

As análises do material empírico produzido foram feitas a partir das transcrições integrais das vídeo-filmagens e anotações de campo da pesquisadora, buscando-se examinar as possibilidades de transformações no curso dos eventos, nas ações em ocorrência e nas relações interpessoais entre os participantes. Para tal, utilizamos elementos da abordagem microgenética; trata-se de uma forma de produção e de análise de material empírico bastante associada ao uso da vídeo-gravação, envolvendo estratégias de filmagem e atividades de transcrição o mais detalhadas possível. Em sua vinculação com a teoria histórico-cultural, tem sido utilizada frequentemente 
na investigação sobre a constituição de sujeitos em contextos educativos, privilegiando o plano das interações e dedicando especial atenção a minúcias que denotem (trans)formações dos/nos processos que se investiga, ainda que não necessariamente consolidadas. Conforme Góes (2000), nesse tipo de método o termo "micro" refere-se a minúcias indiciais, e o termo "genética" indica o interesse em focalizar o movimento, a história dos processos analisados.

É necessário ressaltar que as atividades desenvolvidas com as crianças nessa pesquisa, embora não se tratem, a rigor, de brincadeiras de faz-de-conta, no seu sentido mais estrito, associaram características lúdicas, utilização de elementos simbólicos e o desenvolvimento da capacidade imaginativa, dando ênfase à centralidade das ações da professora junto às crianças, através das quais se buscou promover experiências diversificadas. Dentre as várias atividades do livro da professora e pesquisadora norte-americana Susan Kaiser-Greenland (2010), intitulado The mindful child: how to help your kid manage stress and become happier, kinder, and more compassionate, ${ }^{2}$ ainda sem tradução para o português, escolhemos algumas que avaliamos estarem de acordo com a idade das crianças participantes dessa pesquisa, e que não apresentariam dificuldade de entendimento para sua execução. Para a composição do conjunto de atividades, analisamos também as distinções entre elas, em termos de sua estrutura e nível de complexidade, buscando compor um conjunto diversificado, que mobilizasse o emprego da atenção em condições de realização e a objetos/conteúdos diferentes: atenção ao corpo, atenção a um objeto, atenção a um estímulo auditivo, etc. Além de nosso objetivo geral, tínhamos como hipótese que as atividades que envolvessem mais explicitamente elementos simbólicos teriam potência maior para capturar a atenção das crianças. Esta hipótese não se confirmou, como abordaremos nos resultados. Apresentamos, a seguir, breve descrição das instruções para cada brincadeira.

\section{Atenção no caminhar:}

As crianças se movem pela sala do modo mais suave que conseguirem, como se estivessem andando em cascas de ovos ou num chão delicado de vidro. Elas são orientadas a prestar atenção em cada movimento que fizerem: sentir o músculo da coxa levantar a perna e movê-la para a próxima posição, sentir o pé saindo do chão e voltando a tocar o chão, sentir as mãos e braços no espaço, etc.

\section{Som no espaço:}

Todos sentam em roda. Toca-se um instrumento que produza um som duradouro (exemplo: gongo ou sino). As crianças devem ouvir atentamente o som conforme ele aumenta, diminui e aos poucos desaparece. Quando não mais conseguirem ouvir o som, as crianças devem levantar a mão.

\footnotetext{
A criança atenta: como ajudar sua criança/seu filho a gerenciar o estresse e tornar-se mais feliz, mais amável e mais compassivo (tradução da pesquisadora) Este livro foi ponto de partida para a construção do conjunto de atividades realizadas com as crianças principalmente pelo fato de já ser conhecido e já ter sido colocado em prática pela primeira autora do presente texto, em outras circunstâncias anteriores à pesquisa.
}

\section{Brincadeira do espelho:}

Uma pessoa do grupo faz gestos e/ou movimentos lentos com o corpo, e os demais devem fazer os mesmos movimentos simultaneamente, como se fossem espelhos.

\section{Experimentando uma fruta/alimento:}

As crianças devem focalizar sua atenção numa fruta ou outro alimento, observando-o cuidadosamente como se estivessem vendo-o pela primeira vez. Elas são orientadas a pegar a fruta/alimento e sentir sua textura entre os dedos, perceber suas cores, sentir o seu cheiro e o seu sabor, suas características.

\section{Brincando com os pensamentos:}

As crianças são orientadas a pensar em um objeto (variações da brincadeira: podem pensar em pessoas, locais e situações). Enquanto criam as imagens mentais, elas são orientadas a crer que essas imagens são pensamentos passando por suas mentes. A qualquer momento elas podem mudar as cores e as formas, podem tornar o objeto engraçado, podem pensar em algo completamente diferente.

\section{Buraco do rato:}

As crianças são orientadas a fecharem os olhos e perguntarem a si mesmas: “Qual será meu próximo pensamento?" Elas devem ser como um gato observando o buraco do rato. "Que pensamento sairá do buraco do rato?"

\section{Relaxamento:}

As crianças são orientadas a se deitarem de forma confortável, com os olhos fechados. O ambiente deve estar tranquilo, pode ser usada uma música suave. Cada criança recebe um bichinho de pelúcia ou uma boneca, que deve colocar em cima da barriga, para que observe, enquanto respira, os movimentos abdominais. $\mathrm{O}$ foco de atenção deve estar na respiração e nos movimentos dos bichinhos de pelúcia/bonecas que sobem e descem sobre o abdômen enquanto respiram.

Pesquisadora e professora combinaram dias e horários para o desenvolvimento das atividades com as crianças, elegendo terças e sextas-feiras no período da manhã, portanto duas vezes por semana. Nesses dias, todas as brincadeiras eram realizadas uma após a outra, em sequência variável, estabelecida pela professora, com duração aproximada de trinta a quarenta minutos em cada sessão.

\section{Resultados}

As análises do material empírico foram feitas a partir da imersão nas transcrições, realizada por sucessivas leituras; este trabalho foi permitindo identificar regularidades nas formas de condução das atividades por parte da professora, bem como distinções nos modos pelos quais as crianças aderiram a elas: em todos os dez episódios de uma mesma atividade percebemos uma variação significativa de tempo, e essa variação passou a ser nosso ponto de apoio para o trabalho analítico, buscando identificar razões para que elas ocorressem. Logo a seguir, nos quadros $1 \mathrm{e}$ 2, apresentamos a duração de cada episódio e a duração média de duas atividades, no conjunto de sua realização.

Fractal, Rev. Psicol., v. 32 - n. 1, p. 21-30, 2020 
Quadro 1: Duração de cada episódio da brincadeira "Atenção no caminhar"

\begin{tabular}{|c|c|c|}
\hline ATIVIDADES & DATA & DURAÇÃO \\
\hline \multirow{11}{*}{ ATENÇÃO NO CAMINHAR } & $07 / 11 / 2014$ & $3 \mathrm{~min} 21 \mathrm{seg}$ \\
\hline & $11 / 11 / 2014$ & $3 \mathrm{~min} 23 \mathrm{seg}$ \\
\hline & $14 / 11 / 2014$ & $2 \mathrm{~min} 15 \mathrm{seg}$ \\
\hline & $18 / 11 / 2014$ & $2 \mathrm{~min} 05 \mathrm{seg}$ \\
\hline & $25 / 11 / 2014$ & $2 \min 24 \mathrm{seg}$ \\
\hline & $28 / 11 / 2014$ & $2 \mathrm{~min} 00 \mathrm{seg}$ \\
\hline & $02 / 12 / 2014$ & $2 \min 20 \mathrm{seg}$ \\
\hline & $05 / 12 / 2014$ & $3 \mathrm{~min} 48 \mathrm{seg}$ \\
\hline & $09 / 12 / 2014$ & $3 \mathrm{~min} 43 \mathrm{seg}$ \\
\hline & $16 / 12 / 2014$ & $3 \mathrm{~min} 08 \mathrm{seg}$ \\
\hline & & Média $=2 \min 70 \mathrm{seg}$ \\
\hline
\end{tabular}

Fonte: Elaborado pelas autoras. atividade principal deste período em que os participantes se encontram: o faz-de-conta. Supúnhamos, por isso, que ao serem convocadas a representarem com o corpo ações que simulassem estarem caminhando sobre superfícies fictícias, as crianças teriam maior motivação para prosseguirem na atividade. A professora variou bastante a indicação das superfícies, sendo o conjunto composto por: brasa quente, espinho, caco de vidro, sabão, casca do ovo, flutuando no espaço, água com sabão, fogo, prego, corda bamba, gelatina, água (com piranha), monte de prego, colchão inflável cheio de sabão, arame, brasa vermelha, cobra, barata, brasa viva, brasa de fogão, corda bamba. As crianças aderiram à proposta, mudavam suas formas de caminhar em sintonia com as mudanças de "solo", pareciam se divertir bastante com a brincadeira. Porém, seu enQuadro 2: Duração de cada episódio da brincadeira "Experimentando uma fruta/alimento"

\begin{tabular}{|c|c|c|}
\hline ATIVIDADES & DATA & DURAÇÃO \\
\hline $\begin{array}{c}\text { EXPERIMENTANDO UMA } \\
\text { FRUTA/ALIMENTO }\end{array}$ & $07 / 11 / 2014$ & $6 \mathrm{~min} 30 \mathrm{seg}$ \\
\hline & $11 / 11 / 2014$ & $5 \mathrm{~min} 23 \mathrm{seg}$ \\
\hline & $14 / 11 / 2014$ & $6 \mathrm{~min} 25 \mathrm{seg}$ \\
\hline & $18 / 11 / 2014$ & $12 \mathrm{~min} 30 \mathrm{seg}$ \\
\hline & $25 / 11 / 2014$ & $9 \mathrm{~min} 19 \mathrm{seg}$ \\
\hline & $28 / 11 / 2014$ & $6 \mathrm{~min} 15 \mathrm{seg}$ \\
\hline $02 / 12 / 2014$ & $5 \mathrm{~min} 60 \mathrm{seg}$ \\
\hline $05 / 12 / 2014$ & $8 \mathrm{~min} 00 \mathrm{seg}$ \\
\hline & $09 / 12 / 2014$ & $10 \mathrm{~min} 25 \mathrm{seg}$ \\
\hline
\end{tabular}

Fonte: Elaborado pelas autoras.

Um primeiro aspecto para o qual queremos chamar a atenção é a grande diferença de duração entre as duas atividades focalizadas. Como dissemos, a ordem em que cada brincadeira era realizada era definida pela professora, assim como a sua duração. Pelo acompanhamento do trabalho, podemos dizer que a professora encerrava as brincadeiras e propunha outra, ou encerrava a sessão quando percebia o início de dispersão e/ou de desinteresse das crianças. Sendo assim, podemos entender que, ao contrário do que supúnhamos que iria acontecer - a hipótese de que as atividades que envolvessem mais explicitamente elementos simbólicos (como é o caso de "Atenção no caminhar") teriam potência maior para capturar a atenção das crianças, - foi uma atividade calcada em ato totalmente rotineiro - experimentar um alimento e/ou fruta - a que em média mais tempo envolveu as crianças. ${ }^{3}$

Essa hipótese se apoiava em características estruturais das atividades. Na denominada "Atenção ao caminhar" temos uma proximidade maior com a modalidade de brincadeira indicada na teoria histórico-cultural como a volvimento em termos de duração, em média, foi menor do que a metade da duração, também média, do envolvimento na atividade "Experimentando uma fruta/alimento".

Nas análises do conjunto de episódios identificamos que estratégias como a utilização de estímulos-meio externos não necessariamente simbólicos (tais como alimentos, bichinhos de pelúcia, bolinhas de tênis, bonecas, etc.), a maior clareza da linguagem verbal da professora, mas sobretudo a oportunidade eventualmente dada pela professora para que as crianças coelaborassem as instruções e compartilhassem experiências, fizeram diferença positiva no sentido de adesão e envolvimento nas atividades e desenvolvimento da capacidade de prestarem atenção. A seguir, apresentamos excertos que exemplificam esses movimentos de alternância entre instruções da professora e contribuições das crianças.

\section{Episódio 1 - Atenção no caminhar}

Pf: Sentir o coração. Sentir a batida do seu coração. Põe a mão no peito [todos põem a mão no peito e continuam a andar pela sala]. Pra sentir tem que ser bem devagar. Não! Tem que pôr a mão no coração, $L$.

$\mathrm{N}$ : Aqui é o pulmão, aqui que é o coração! [N. fala e mostra a localização do coração no próprio corpo para o amigo, que parece não saber onde fica o coração].

M: Não é! [outra criança discorda de N.]

N: Pulmão. O dia que você for no médico... Quando você for no médico...

P: Aqui é o pulmão? [pergunta R.]

\footnotetext{
A atividade "Relaxamento" teve duração média muito próxima (Média= $7 \mathrm{~min}-$ 44seg.).
} 


\section{Episódio 2 - Atenção no caminhar}

Pf: Vocês podem ver quem está andando devagar é quem está realmente sentindo a batida do coração [pausa]. Agora pode tirar a mão do peito, vamos fazer de conta que estamos pisando...

As crianças vão dando sugestões em voz alta.

$\mathrm{N}$ : Na gelatina.

P: No sabão.

Crianças mudam o modo de caminhar, com movimentos que simulam estarem escorregando.

Pf: No arame.

Crianças: Aiiii!...

P: Arame dói, machuca.

S: Arame tem ponta afiada!

P: É ferro.

Pf: É um ferro que se você pisar "espinha”. Agora cada um pode ir andando no seu lugar, bem devagarzinho [as crianças vão andando e sentando na roda de novo].

\section{Episódio 3 - Experimentando uma fruta/alimento}

Pf: Olhando. Eu vou perguntar... T., fala uma coisa que você está vendo nesse alimento. [T. não quer falar, a professora se dirige a outra criança] J., olha para ela, o que você está vendo? O que você pode falar?

J: Tem uma linha.

Pf: K., olha que eu vou perguntar. Presta atenção. Olha. T.! Olha e fala uma coisa que tem nesse amendoim.

T: Tem um monte de pintinhas.

Pf: D., o que você tem pra falar?

D: Tem um buraco no meio.

\section{Episódio 4 - Experimentando uma fruta/alimento}

Pf: Tem outras coisas que parecem com essa fruta? Tem outras coisas que tem o formato dessa fruta...

$\mathrm{S}$ : Rabanete.

W: Bexiga.

Pf: Olha bem para essa fruta, a cor dela...

D: Essa bexiga é de comer..

W: Lógico.

\section{Episódio 5 - Buraco do rato}

A professora passa a perguntar para algumas crianças o que elas pensaram. Chama a K. para sentar perto dela. Pede para P. voltar para o lugar. Reorganiza a roda e diz que vai perguntar para quem estiver bem quietinho.

D: O ratinho aprontou um monte de flores e as abelhas vieram...

E: Tinha um carro e ele montou no carro e saiu... Foi viajar!

W: [Inaudível]
D: O que ela falou? [a criança não ouviu o que a colega disse].

W: Ele encontrou um jacaré.

A: Ele encontrou os amigos dele e ele achou um dragão.

P: Ele entrou dentro da magia e virou um príncipe.

B: Ele encontrou insetos.

D: Virou o Superman.

Algumas crianças não quiseram falar.

Pf: Não imaginou nada? [pergunta a professora quando a criança não quer falar].

C: Ele encontrou uma ratinha!

G: Ele foi pegar comida.

A professora começa a reorganizar a roda, algumas crianças querem falar, mas ela finaliza a atividade.

\section{Episódio 6 - Som no espaço}

D: Tia, vira do outro lado? [pedindo para a professora tocar do outro lado do sino].

Pf: Desse lado, ele faz também!

A professora toca o sino.

D: Legal!

Pf: Vamos ouvir o barulho.

Pf: Deste lado, deste aqui não dá [mostrando que se bater dentro do sino ele não emite som. As crianças pedem para bater por fora].

F: Do lado de fora... [se referindo ao sino]

A professora então toca o sino longamente, e uma das crianças diz que parece que a parede vai desmoronar.

Pf: Parece que a parede vai desmoronar...? [a professora acha graça na fala da criança]

S: Cair em cima da gente!

Em contrapartida, nos episódios de menor duração prevalecem esforços por parte da professora e da monitora ${ }^{4}$ para que as crianças seguissem as instruções dadas, sem introduzir nelas suas contribuições. Exemplos deste tipo de mediação são apresentados a seguir.

\section{Episódio 7 - Atenção no caminhar}

Pf: Nesse momento do "Atenção no caminhar" quando eu falar pra vocês: "Atenção”!, não pode falar! Como que você vai ter atenção no barulho do seu joelho, no barulho do seu passo se você tá falando com o amigo, mexendo com o amigo, olhando pro amigo? Você tem que pensar em você! Em pé, e só as coordenadas eu que vou dar; não é para ficar falando, dando sugestões.

$[\ldots]$

Pf: Tudo no pensamento!

\section{$[\ldots]$}

${ }^{4}$ Em alguns episódios a monitora da turma também esteve presente, participando das atividades.

Fractal, Rev. Psicol., v. 32 - n. 1, p. 21-30, 2020 
Monitora: $O$ pensamento não fala! A., o pensamento não fala!

\section{Episódio 8 - Experimentando uma fruta/alimento}

Pf: Olhando para a fruta, pensando na fruta! Pensar é falar? Crs: Não!...

Quando as contribuições são aceitas pela professora e partilhadas com a turma, as crianças surpreendem, pois formulam uma diversidade de respostas que enriquece a atividade, demonstrando, claramente, que estavam prestando atenção às instruções verbais/comandos da professora. $\mathrm{Na}$ /pela linguagem torna-se possível a realização da atividade, instituem-se relações entre os participantes da roda, faz-se com que experienciem e partilhem a imaginação. As crianças conseguem perceber e descrever minúcias sobre os alimentos experimentados, são capazes de comparar suas características, participam ativamente da atividade, que parece ser muito significativa para eles, considerando-se que o tempo de duração se prolonga e o envolvimento se mantém até o momento em que a professora a finaliza. Uma atividade tão banal como comer um amendoim é experimentada de um outro modo, prazerosamente, com as possibilidades de explorar o alimento em atos organizados pela linguagem da professora ("olha para ele, o que você está vendo?"; “o que você pode falar?"; “crianças, e a cor e o formato?”) e das crianças ("tem um monte de pintinhas"; "é coquinho pequeno..."; "tem um buraco no meio"; "tem sal”; "tem uma linha"; "no final é docinho"). A duração de 12 minutos e 30 segundos na atividade de comer três ou quatro amendoins pode ser tomada como um contraponto à asserção comumente encontrada nos manuais de Psicologia de que as crianças pré-escolares não sustentam ainda por muito tempo sua atenção; verificamos que isto tende a se modificar se a atividade tiver sentido e for desafiadora para elas: para que a atenção se mantenha, é de extrema relevância o sentido que a atividade tem para a criança, e este sentido, na pesquisa desenvolvida, foi sendo construído especialmente pelas possibilidades de participação. As instruções verbais da professora fazem com que as crianças prestem atenção em algo que normalmente acontece automaticamente na vida cotidiana, propiciando novos níveis de consciência sobre si e sobre o mundo.

Em outras situações, porém, a professora não permite a contribuição das crianças, centraliza as instruções verbais e exerce papel bastante controlador, demarcando seu lugar de autoridade. Sabemos que nessa faixa etária ficar totalmente em silêncio requer um grande esforço para a criança e vai na contramão das possibilidades de envolvimento nas atividades e de realização de suas ações e pensamentos, pois ela organiza-os e planeja-os emitindo comandos verbais para si mesma (função prioritária da fala egocêntrica, segundo Vigotski), enquanto executa uma tarefa, atividade ou brincadeira.

Em algumas circunstâncias, a professora poderia ter razão, já que a linguagem também pode atrapalhar, quando as crianças começam a falar de outras coisas, que podem desfocar da atividade que estão realizando, con- tribuindo para a dispersão; não é qualquer forma de linguagem que é sempre bem-vinda; mas, nas transcrições, surgem muitas contribuições que poderiam ter sido bastante pertinentes à atividade e à manutenção da atenção em seu desenrolar e que não foram aproveitadas pela professora, principalmente quando pede para as crianças não falarem, para somente pensarem! Ou seja, suas intervenções e esforços para que as crianças não falassem não são "seletivos" (buscar impedir a dispersão ou permitir e estimular o uso da linguagem para aprimorar a regulação do comportamento próprio e do outro) e aí está o problema.

Queremos, por fim, destacar que ao longo das análises dos episódios um tipo de intervenção das crianças foi se mostrando muito interessante no campo da discussão sobre a constituição e desenvolvimento da atenção mediada: em algumas situações as crianças, de certo modo, invertem a dinâmica em que a professora dá os comandos e, ao invés de apenas segui-los, solicitam que a professora os apresente, por vezes procurando corrigi-la, como podemos ler nos trechos abaixo:

\section{Episódio 9 - Experimentando uma fruta/alimento (confeito MM)}

Pf: Agora nós vamos colocar na boca, não é pra mastigar, é pra sentir o sabor. Não põe mais a mão na boca.

D: Ô tia, cheirar!

Pf: Eu já cheirei [outras crianças responderam que já cheiraram também].

\section{Episódio 10 - Experimentando uma fruta/alimento (uva)}

Pf: Agora você tira o carocinho [era o cabinho] e agora vamos comer de pedacinho pra sentir o sabor? Sem mastigar! Pega um pedaço e... [ela morde a uva, tira um pedacinho, mostrando para as crianças].

A.: E o cheiro? [a criança se referiu às atividades anteriores em que, antes de comer, cheiravam primeiro]

\section{Episódio 11 - Experimentando uma fruta/alimento (uva)}

Pf: Agora você pode experimentar, sem mastigar, só põe na boca assim, ó...[algumas crianças repetem os gestos da professora].

S: Só com a língua, né, tia?

\section{Episódio 11 - Experimentando uma fruta/alimento (morango)}

Pf: Tira um pedacinho.

R: Não, tia, é na língua... [se referindo à forma de experimentar que já tinham feito anteriormente com a professora, que começava somente sentindo o alimento na língua, sem mastigar.]

\section{Episódio 9 - Experimentando uma fruta/alimento (morango)}

LF: [olha, cheira o morango e diz]: É bom!

$\mathrm{N}$ : Tia, a gente vai comer que horas? 
Pf: Mais um pedacinho, ele tem semente?

As crianças estão bem alegres e participantes na atividade.

T: Tem! E muita!

\section{Episódio 12 - Atenção no caminhar}

\section{N: Tia, onde a gente está pisando?}

Temos, em vários momentos dos episódios, exemplos significativos de linguagem externalizada, para o "outro", numa função especial, quando alguns alunos pedem que a professora comande a atenção e as ações deles. Isto sinaliza que as crianças internalizaram as instruções verbais da professora, o sentido das orientações das instruções verbais na atividade, e solicitavam para a professora a organização da atenção do grupo. No decorrer das atividades, as enunciações em que pedem para tocar o sino de outra forma e solicitam a instrução para cheirar a fruta funcionam como uma chave para a descoberta do poder da linguagem no funcionamento psicológico; porque elas estão internalizando isso, e esse é o diferencial que elas podem usar em outras situações de suas relações com o alimento, com outras brincadeiras e com a vida. É a palavra, é a linguagem que a criança internaliza e a instrução verbal dada que passam a ser uma instrução que ela vai, gradualmente, sendo capaz de usar para regular o seu comportamento. E é isso que pode se generalizar para outras situações que tenham graus de proximidade e similaridade com a situação da qual tal processo se originou. Sentir o cheiro de uma fruta, de um pedaço de chocolate, de um amendoim, explorá-los primeiramente com a língua, conter seu impulso e desejo de comê-los imediatamente, servem para modificar a relação das crianças com qualquer alimento; quando a professora nos diz na entrevista final que algumas crianças estão reproduzindo estas orientações em casa, que estão ensinando seus pais a mudarem sua relação com os alimentos, através da instrução verbal que elas receberam da professora, fica evidente o poder da linguagem em exemplos concretos daquilo que teoricamente apresentamos.

No esforço de dominar e orientar a atenção da criança, ocorre um intenso trabalho interno por parte dela, e há que se considerar, no percurso de seu desenvolvimento, a qualidade das mediações, dos signos e dos instrumentos culturais a que teve/tem acesso.

\section{Considerações finais}

Nesta pesquisa desenvolvemos, em colaboração com a professora, algumas estratégias e práticas pedagógicas que entendemos serem produtivas para o desenvolvimento da atenção mediada das crianças; analisamos, tomando inicialmente como referência o tempo de duração das atividades, como em diferentes edições de uma mesma brincadeira a atenção das crianças pode ser sustentada de maneiras distintas. $\mathrm{Na}$ busca das razões pelas quais isso acontece, evidenciamos que, embora a proposta geral de cada tipo de atividade fosse a mesma, o modo como elas foram conduzidas em cada edição variou, em especial no que diz respeito às condições de participação das crianças, outorgada ou não pela professora.
Não existe garantia - nem foi essa nossa pretensão de que as atividades assim como foram realizadas ao longo dos dez encontros funcionem depois como uma receita prescritiva para o trabalho da professora ou em qualquer outro contexto educacional; mas é possível ressaltar características dessas atividades, que podemos empreender para trabalhar a capacidade atencional das crianças; isto não desqualifica as atividades propostas na pesquisa; pelo contrário, demonstra que as práticas pedagógicas potencialmente produtivas para o desenvolvimento da atenção devem considerar a linguagem como o instrumento privilegiado de interação entre o grupo; que a mediação da professora é condição imprescindível para dirigir e orientar a atenção das crianças; que as instruções verbais da professora têm o poder de envolver e manter as crianças participantes; que o tempo de duração das atividades deve ser dosado; que a riqueza de contribuições trazidas pelas crianças favorece o diálogo, a troca de experiências no grupo e seu envolvimento naquilo que faz; que as crianças possam trabalhar sensações e movimentos corporais, possam experimentar, tocar, sentir, explorar e manipular os objetos que constituem o mundo que as rodeia de modos diferenciados; e, por fim, que os barulhos, a movimentação, o riso e o alvoroço, tão característicos das crianças de cinco e seis anos, sejam permitidos, respeitados e incorporados nas interações que as crianças estabelecem entre si e com as demais pessoas que as cercam.

Pensamos que podemos contribuir para superar dois equívocos para o melhor entendimento do processo de desenvolvimento da atenção, com nossos resultados. Em primeiro lugar, a importância de não se considerar a atenção como capacidade inata/natural, relacionada com o âmbito orgânico, e nem que as dificuldades e distúrbios de aprendizagem podem ser resolvidos com a medicalização dos sintomas. Em segundo lugar, considerar que, para o aprimoramento do funcionamento da atenção das crianças, a mediação pedagógica não tem efeitos generalizados sobre seu desenvolvimento (destacando que a atenção não é uma capacidade genérica, que independe de aspectos específicos, como o tipo de atividade, tipo de instrução, uso de recursos mediacionais). Ou seja, finalizamos sublinhando que a melhora da atenção em certas atividades não necessariamente redunda em melhoras como capacidade geral, aplicável a quaisquer atividades. Concluímos, ainda, que devemos trabalhar intensamente o papel da linguagem verbal externalizada - ao invés de coibi-la, ensinar modos de utilizá-la que permitam graus sucessivos de seu poder de autorregulação.

O trabalho de inclusão e de organização das práticas pedagógicas que selecionamos e desenvolvemos com as crianças nos permite avançar no que sabemos sobre o processo de constituição e desenvolvimento da atenção; permite-nos compreender as condições mais ou menos favoráveis para esse funcionamento e aprimoramento. Há muito ainda a se investigar sobre esse processo. Vigotski, Luria e Leontiev, tendo realizado importantes esforços nesta direção, deixaram em aberto algumas questões; almejamos que nosso trabalho seja uma contribuição, mesmo que modesta, na busca de avanços dos conhecimentos sobre o tema. 


\section{Informações sobre as autoras:}

Lucimar Delman Lains

(iD) https://orcid.org/0000-0002-4799-1863

(9) http://lattes.cnpq.br/7579263087604576

Graduada em Pedagogia (1986). Possui especialização em Educação

e Psicopedagogia pela Pontifícia Universidade Católica de Campinas-PUCCAMP (2006) e especialização em EAD/ Educação à Distância pelo Instituto de Ensino Superior COC (2009). Mestranda no Programa Stricto Sensu de Educação da Pontifícia Universidade Católica de Campinas- PPGE/PUCCAMP (2014-2016).

Maria Silvia Pinto de Moura Librandi da Rocha

(iD) https://orcid.org/0000-0002-6001-1292

(9) http://lattes.cnpq.br/5277455644761315

Docente do Programa de Pós-Graduação em Educação da Pontifícia Universidade Católica de Campinas. É líder do Grupo de Pesquisa Formação e Trabalho Docente, em que são desenvolvidos trabalhos na Linha de Pesquisa "Formação de Professores e Práticas Pedagógicas". Realiza pesquisas na área de Psicologia e Educação, principalmente nos seguintes temas, fundamentados na perspectiva da Psicologia Histórico-cultural: desenvolvimento psicológico infantil, funções psicológicas superiores, atividade lúdica, alfabetização e letramento, relacionando-os com práticas pedagógicas e formação de professores da Educação Infantil e do Ensino Fundamental (anos iniciais). É assessora científica da FAPESP desde 2007. Possui graduação em Psicologia pela Pontifícia Universidade Católica de Campinas (1981), graduação em Licenciatura em Psicologia pela Pontifícia Universidade Católica de Campinas (1980), aprimoramento em Psicopedagogia pela USP/Ribeirão Preto (1983), mestrado em Educação pela Universidade Estadual de Campinas (1994) e doutorado em Educação pela Universidade Estadual de Campinas (2005). Em 2015 realizou pós-doutoramento na Universidade de Barcelona, sob orientação do Prof. Dr. Eduardo Marti.

\section{Contribuições das autoras:}

Ambas as autoras colaboraram ao longo do processo, desde a elaboração até a revisão final do manuscrito. As autoras aprovaram o manuscrito final para publicação.

\section{Como citar este artigo:}

\section{ABNT}

LAINS, Lucimar Delman; ROCHA, Maria Silvia Pinto de Moura Librandi da. Desenvolvimento da atenção mediada e sua relação com práticas pedagógicas. Fractal: Revista de Psicologia, Niterói, v. 32, n. 1, p. 21-30, jan./abr. 2020. https://doi.org/10.22409/1984$0292 /$ v32i1/5634

APA

Lains, L. D., \& Rocha, M. S. P. M. L. (2020, Janeiro/Abril) Desenvolvimento da atenção mediada e sua relação com práticas pedagógicas. Fractal: Revista de Psicologia, 32(1), 21-30. doi: https://doi.org/10.22409/1984-0292/v32i1/5634

\section{Referências}

BARKLEY, Russel. Transtorno de déficit de atenção/ hiperatividade (TDAH): guia completo para pais, professores e profissionais da saúde. Porto Alegre: Artmed, 2002.

BONDEZAN, Andreia Nakamura. Desenvolvimento da percepção e da atenção: a relevância das relações sócioeducacionais. 2006. Dissertação (Mestrado)-Programa de Pós-graduação em Educação da Universidade Estadual de Maringá, Maringá, 2006. Disponível em: www.ppe.uem.br/ dissertacoes/2006-Andreia Bondezan.pdf. Acesso em: 6 abr 2014.
EIDT, Nadia; FERRACIOLI, Marcelo. O ensino escolar e o desenvolvimento da atenção e da vontade. In: ARCE, Alessandra; MARTINS, Lígia Márcia (Org.). Quem tem medo de ensinar na educação infantil? Em defesa do ato de ensinar. Campinas: Alínea, 2007. p. 93-123.

EIDT, Nadia; TULESKI, Silvana. Transtorno de déficit de atenção/hiperatividade e psicologia histórico-cultural. Cadernos de Pesquisa, São Paulo, v. 40, n. 139, p. 121-146, jan./abr. 2010. http://dx.doi.org/10.1590/S0100-15742010000100007

EIDT, Nadia; TULESKI, Silvana; FRANCO, Adriana. Atenção não nasce pronta: o desenvolvimento da atenção voluntária como alternativa à medicalização. Nuances: estudos sobre Educação, Presidente Prudente, v. 25, n. 1, p. 78-96, jan./abr. 2014. http://dx.doi.org/10.14572/nuances.v25i1.2759

FERRACIOLI, Marcelo Ubiali. Desenvolvimento da atenção voluntária em crianças dos anos iniciais do ensino fundamental: determinantes pedagógicos para a educação escolar. 2018. Tese (Doutorado)-Programa de Pós-graduação em Educação Escolar, Universidade Estadual Paulista Júlio de Mesquita Filho, Araraquara, 2018. Disponível em: http://wwws.fclar. unesp.br/agenda-pos/educacao escolar/4733.pdf. Acesso em: 10 jan. 2020.

GÓES, Maria Cecília Rafael de. A abordagem microgenética na matriz histórico-cultural: uma perspectiva para o estudo da constituição da subjetividade. Cadernos Cedes, v. 20, n. 50, p. 9-25, 2000. http://dx.doi.org/10.1590/S010132622000000100002

KAISER-GREENLAND, Susan. The mindful child: how to help your kid manage stress and become happier, kinder, and more compassionate. New York: Free Press, 2010

LEITE, Hilusca; TULESKI, Silvana. Psicologia históricocultural e desenvolvimento da atenção voluntária: novo entendimento para o TDAH. Psicologia Escolar Educacional, Maringá, v. 15, n. 1, p. 111-119, jan./jun. 2011. http://dx.doi. org/10.1590/S1413-85572011000100012

LUCENA, Jéssica Elise Echs. $O$ desenvolvimento da atenção voluntária na educação infantil: contribuições da Psicologia Histórico-Cultural para processos educativos e práticas pedagógicas. 2016. Dissertação (Mestrado)-Programa de Pósgraduação em Psicologia, Universidade Estadual de Maringá, Maringá, 2016. Disponível em: http://repositorio.uem.br:8080/ jspui/handle/1/5679? mode=full. Acesso em: 10 jan. 2020.

LURIA, Alexander. Curso de Psicologia Geral. Rio de Janeiro: Civilização Brasileira, 1979. v. 3.

MOYSÉS, Maria Aparecida Affonso; COLLARES, Cecília Azevedo Lima. Inteligência abstraída, crianças silenciadas: as avaliações de inteligência. Psicologia USP, São Paulo, v. 8 , n. 1, p. $63-89,1997$. http://dx.doi.org/10.1590/S010365641997000100005

RABATINI, Vanessa Gertrudes. O desenvolvimento da atenção na educação do pré-escolar: uma análise a partir da psicologia histórico-cultural e da pedagogia histórico-crítica. 2016. Tese (Doutorado)-Programa de Pós-graduação em Educação Escolar, Universidade Estadual Paulista Júlio de Mesquita Filho, Araraquara, 2016. Disponível em: http://wwws.fclar. unesp.br/agenda-pos/educacao_escolar/3808.pdf. Acesso em: 10 jan. 2020. 
ROSA, Solange Aparecida da. Dificuldades de atenção e hiperatividade na perspectiva histórico-cultural. Psicologia Escolar e Educacional, Maringá, v. 15, n. 1, p. 143-150, jan.jun. 2011. http://dx.doi.org/10.1590/S1413-85572011000100015

TULESKI, Silvana Calvo; EIDT, Nadia Mara. Repensando os distúrbios de aprendizagem a partir da psicologia históricocultural. Psicologia em Estudo, Maringá, v. 12, n. 3, p. 531-540, set./dez. 2007. http://dx.doi.org/10.1590/S141373722007000300010

VYGOTSKI, Lev. Historia del desarrollo de las funciones psíquicas superiores. Madrid: Visor, 1996. Obras escogidas, v. 3. 